
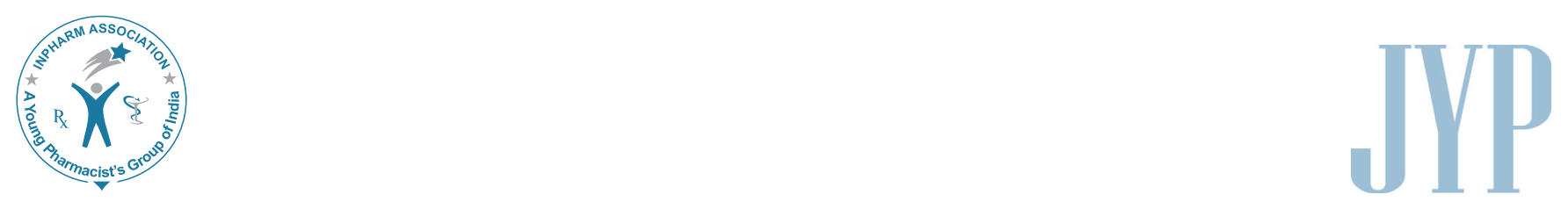

\title{
Human in Wi-Fi zone!
}

In the current era, wireless network/Wi-Fi occupied important and significant place in our life. Wherever we travel, and residing and expect to be online and always searching for wireless/Wi-Fi internet connection to check the email, read blogs, scientific/political updates, social activities etc. If we ask any youth "what mobile you want?," immediately they will say mobile with features of global positioning system, general packet radio service, Wi-Fi, Bluetooth, 3G/4G networking facilities, front and back camera with 6-10 inch screen and this mobile configuration enable user to use wireless/Wi-Fi networks. Most of the places, we observe that people in society have a tendency to update the current status in social media's and forgetting real enjoyments, and this may become habituation, later it will become a kind of addictive behaviour. Including me, no one will against for adopting lifestyle with recent developments, but sometimes it may lead us to be living us with calculative/mechanical life.

In olden days, human lifespan was around 100-120 years but it was get reduced to 60-100 years in the modern era because advancement in cultivation technology, transportation, networking and informative technology. When we are developing same time, we are trying our self to change in our lifestyle in terms of changing in our workflow, sleeping cycle and reduction in social life. Using advanced technology is good and better, but same time the technology reducing our family interaction and increasing health related hazards. Now-a-days, we are buying the risk by paying money. For example, cultivation and use of genetically modified agriculture product may fulfill our needs, but what about the safety and longtime usage of genetically modified product. Kuiper $e t$ al. assessed the safety issue of genetically modified food substances and briefly explained in his research paper. ${ }^{1}$

Now-a-days, we are using Wi-Fi network without understating its adverse health risk. Wi-Fi modems are using dangerous electromagnetic radiation to send their signals to our computers/smartphone through ramparts. ${ }^{2}$ While using/leaving in Wi-Fi zone along with computer/ smart phones, we also tend to get expose with massive electromagnetic radiation which may not good for our health. We may feel comfortable using in Wi-Fi network, but we never think about the duration personal exposure with electromagnetic radiation. Sometimes, the technologist may think only small/low gigahertz frequency level may not problem, but the problem here is chronic exposure. User safety is questionable, if user is getting exposed with low gigahertz frequency level of electromagnetic radiation for a long time/chronically.

On $2^{\text {nd }}$ April, 2014, Global Healing Center published the 10 shocking facts about the health dangers of Wi-Fi radiation, which including development of insomnia, alteration/disrupt normal cellular development, details and reduce brain function, provokes cardiac stress, and increase the risk of development of cancer. ${ }^{3}$ The report of Karolinska Institute saying that, Wi-Fi is dangerous to children and pregnant women, and this may increase the risk of cancer and increase the risk of development of neurological disease, reproductive and development impairments. ${ }^{4}$ There are some more evidence for wireless network induced oxidative stress in rodents. ${ }^{5,6}$ Some people are reported electromagnetic hypersensitivity symptoms such as fatigue, headache, muscle stress, sleep disturbances, stress, etc. with presence of a Wi-Fi router in their workplace and residence. ${ }^{7}$

Global exposures to developing wireless technology for using a cellular phone, Wi-Fi, physiological monitor, etc., have serious public health consequences. ${ }^{8}$ So far, there are no strong recommendations available for ensuring the health safety of using Wi-Fi modem. However Health Canada, stated radio frequency energy from Wi-Fi equipment and other wireless devices as "possibly carcinogenic to human" (Internationally Agency for Research on Cancer 2011 report).

Instead of discussing whether Wi-Fi is good or bad, we can reduce the use of our personal Wi-Fi modem by switching off Wi-Fi modem whenever we are not using. One can 
thing if I switching off Wi-Fi modem will have a significant changes in society? Answer is YES. Instead of thinking others, everyone can take the lead to save our environment from our end by reducing use of our personal source of non-ionizing radiation that may have a greater effect in society; thereby we can give a healthy environment to next generation people. In 2013, Mr. Script also suggested keeping router at least $3 \mathrm{~m}$ away from user body and try to switch off the laptop's Wi-Fi card if user is not using. ${ }^{7}$

Here one more problem is along with user whoever residing in the zone of wireless/Wi-Fi network unknowingly getting exposed without their knowledge/consent. Who is going to answer for the people those are unknowingly getting exposed with dangerous electromagnetic radiation?

\section{Subramani Parasuraman* Editor-in-Chief, Journal of Young Pharmacists \\ *Address for correspondence: Dr. S. Parasuraman, Faculty of Pharmacy, AIMST University, Bedong 08100, Malaysia. E-mail: jypeditor@gmail.com}

\section{REFERENCES}

1. Kuiper HA, Kleter GA, Noteborn HP, Kok EJ. Assessment of the food safety issues related to genetically modified foods. Plant J. 2001;27:503-28.
2. Wi-Fi health dangers \& radiation health effects. Available from: http:// www.safespaceprotection.com/electrostress-from-wireless-routers.aspx. [Last accessed on 2014 Aug 03].

3. 10 shocking facts about the health dangers of Wi-Fi. Available from: http:// www.globalhealingcenter.com/natural-health/10-shocking-facts-healthdangers-wifi/. [Last accessed on 2014 Aug 04].

4. Karolinska Institute Department of Neuroscience, Stockholm, Sweden. LATEST WARNING: Wi-Fi Dangerous to Children and Pregnant Women - Must Read! Available from: http://www.safeinschool. $\operatorname{org} / 2011 / 02 /$ latest-in-scientific-world-on-health.html. [Last accessed on 2014 Aug 04].

5. Naziroğlu M, Gümral N. Modulator effects of L-carnitine and selenium on wireless devices $(2.45 \mathrm{GHz})$-induced oxidative stress and electroencephalography records in brain of rat. Int J Radiat Biol. 2009;85:680-9.

6. Nazıroğlu M, Çelik Ö, Özgül C, Çiğ B, Doğan S, Bal R, et al. Melatonin modulates wireless $(2.45 \mathrm{GHz})$-induced oxidative injury through TRPM2 and voltage gated $\mathrm{Ca}(2+)$ channels in brain and dorsal root ganglion in rat. Physiol Behav. 2012;105:683-92.

7. Script J. Is Wifi signal harmful to human body? Available in http://www. coredore.com/gadgets/is-wifi-signal-harmful-to-human-body/. [Last accessed on 2014 Aug 04].

8. Sage C, Carpenter DO. Public health implications of wireless technologies. Pathophysiology. 2009;16:233-46.

9. Safety of Wi-Fi Equipment. Health Canada. Available in http://www.hc-sc. gc.ca/hl-vs/alt_formats/pdf/iyh-vsv/prod/wifi-eng.pdf. [Last accessed on 2014 Aug 04].

\begin{tabular}{|l|l|}
\hline \multicolumn{2}{|c|}{ Access this article online } \\
\hline \multirow{2}{*}{ Journal Sponsor } & \\
\hline & $\begin{array}{l}\text { Website: } \\
\text { www.jyoungpharm.org }\end{array}$ \\
\cline { 2 - 2 } & \\
\cline { 2 - 2 } & DoI: \\
& $10.5530 / j y p .2014 .4 .1$ \\
& \\
\hline
\end{tabular}

